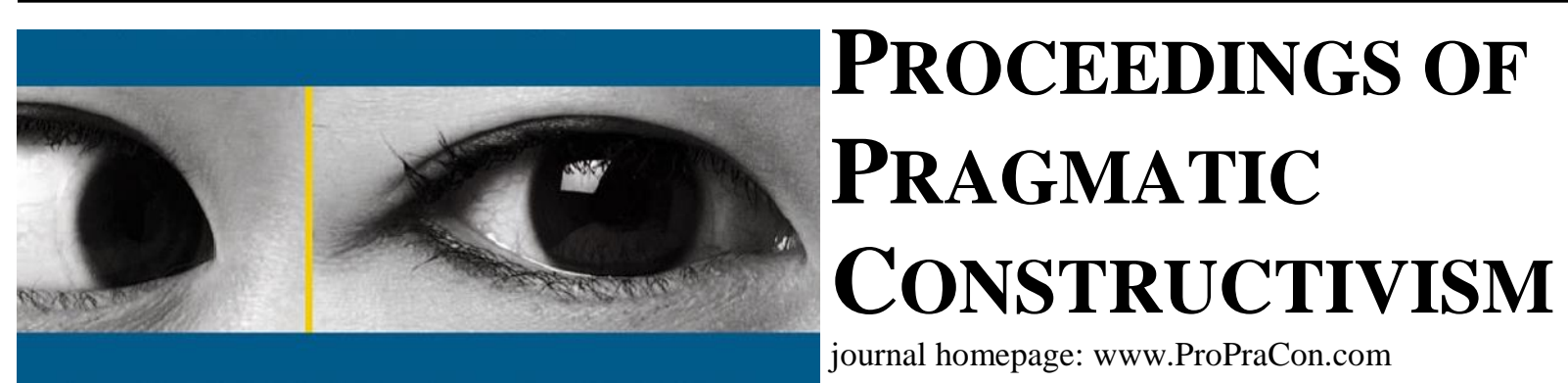

\title{
IT and Paranoiac Rule
}

\author{
Lennart Nørreklit \\ Professor Emeritus, Aalborg University, Denmark. \\ E-mail: lennartnorreklit@gmail.com
}

This study analyzes effects of the large-scale use of state of art IT systems as a tool to control all aspects of human activity that we are witnessing. It is prompted by amongst other some worrying changes in the style of communicative social rule. Many studies have pointed out trends that appear irrational: that now live in period of post truth and pathos - and not in a period of high knowledge.

This analysis is based on the assumption that the use of IT based control marks a shift in the communicative processes in society. It is a change from a form of communication that is based on free language game as the basis of human interaction to a communication that is heavily controlled by IT systems.

The free language gaming is the very social factory in that it produces the social nature of man. In the free language games the dimensions of reality construction are automatically integrated by the participants - presuming they do intend the game in which they participate to function. The free language gaming enables people to develop many layered cognitive structures that enable them to communicate and coordinate across diverging perspectives and levels of knowledge.

However, the language in use in IT systems is very different. As long as IT systems are tools used by people this may not be a problem. But when IT systems are used to control people, then it becomes a very decisive issue, because then the conceptualizations made in the controlling IT systems overrule the integrative language of free language gaming thereby making the advanced many layered cognition of the participants irrelevant or even a draw hindrance. This type of IT based rule seems to be implemented all over in modern societies today.

To understand some the effects of IT based rule means, we must consider what type of language IT systems use used to dominate and even replace the language of free and integrative language game. Some important points are: IT languages are digital, formalized, reductionist (no integration, one-dimensional) languages often with a hidden or unknown meaning and certainly not controlled by the users (not free). It bears affinity to the ideals of the ideal of a universal logical language logical of logical positivism notably that of Wittgenstein’s Tractatus (1921).

The surprising question is: how can a logically clear language lead to irrationality and post truth?

Interestingly, the Tractatus itself draws important consequences of this language: namely that important phenomena like values, ethics and meaning are not part of the world of facts depicted in this language.

This dramatic conclusion was more puzzling than alarming when such types of apparent consequences were presented and discussed. However, today, when we notice that IT languages that are this type of language is use to control human activities, then these theoretical consequences get a whole new meaning. I.e. we must consider whether some of the consequences we do notice in practice are not in reality at least partly the consequences that were theoretically predicted in an abstract way. After all, if the free language game is the very social factory, then any oppression of it must have significant consequences.

The 'cognitive content' of the IT language of the control systems is by dictate imposed on the users. Thereby it overrules their complex and many layered cognitive capacities replacing it with something that may be unknown. It is hidden in the mostly unknown operationalization in the IT language. And as far as it is known, it is often considered inadequate and even simplistic or wrong by professional users. The effect on the users' cognitive level of communication is obviously negative. It virtually disappears and is replaced by emotive struggles. Also leaders with 
limited knowledge of the content they are managing, and certainly less knowledge than the people they manage, should not listen to their professionals because the IT system defines the rule.

Thus, if the leaders stick to the IT based control, then the logos of reasoning amongst people involved in organizing the practice collapses as irrelevant. No narrative, no theory, no deeper understanding or advanced skill is in demand. Only obedience to the prescriptions is acceptable. Professional knowledge and understanding is then outdated.

Also from a leadership point of view, the IT control tools are not based on reason. Leadership rhetoric must find alternative to leadership by logos, and the alternative is leadership by pathos, i.e. by developing communicative strategies that mobilize emotional energies. Leadership communication needs to rule by establishing pathos - especially by establishing fear of not being loyal, i.e. obedient, instead of establishing understanding. This is a typically fascist leadership style. Theories of decent leadership from the last half of the 20th century suddenly seem forgotten.

The way to lead based pathos and not on insight and reflection is to define the communicative rules in typically paranoiac ways: A target is selected. Now everything in relation to the target is by definition bad. It does not matter that the same thing is considered something OK or even good in relation to other possible targets. This is the nature of paranoia: the target defines what the evidence means. If a person or a viewpoint is targeted negatively, then everything in relation the target is considered bad - although the same thing in relations to other viewpoints or persons is innocent or even good. And when this is established with sufficient strength, the person is defined as a villain or the viewpoint as stupid then the target may finally be attacked. This happens is in high level politics as well in business and social institution. 